\title{
O Banco de Dados e o Plano Nacional de Estatísticas Básicas
}

José Francisco de Albuquerque Lins

Capitão-de-Mar-e-Guerra; entre outros cargos e funções exerceu a Chefia do Núcleo da Secretaria Geral da Marinha em Brasilia

\section{INTRODUÇÃO}

Em ensaio intitulado o BANCO DE DADOS E A REFORMA ADMINISTRATIVA $\left(^{\circ}\right)$ mostramos como imaginamos que deva funcionar o BANCO NACIONAL DE DADOS, segundo os Princípios Fundamentais que norteiam a REFORMA ADMINISTRATIVA a ser implantada no País, o que levaria à instituição de uma estrutura de organização que pode ser indicada pela Figura, onde são mostrados os três níveis básicos através dos quais se realizam todas as ações da Política Nacional:

nivel 1 - NACIONAL;

nível 2 - REGIONAL ou ESTADUAL; e

nível 3 - LOCAL ou MUNICIPAL.

Demonstramos que, para obter a mais perfeita coordenação e a mais completa integração de esforços no desenvolvimento das ações do Governo, com o fim de serem atingidos os OBJETIVOS NACIONAIS PERMANENTES, que é o propósito final da POLITICA NACIONAL, deveríamos setorializar a coordenação segundo as quatro expressões básicas do PODER NACIO(") A ser oportunamente publicado na "Revista do Serviço Público". 
NAL, ou seja, estabelecer a cadeia de coordenação nos campos político, econômico, psicossocial e militar, propondo uma METODOLOGIA para a formulação, orientação e controle da Política Nacional, conforme idealizamos. vés de:

Indicamos, também, que deveria a estrutura funcionar atra-

a) uma direção centralizada, onde se efetuará o planejamento, a coordenação e o controle;

b) uma execução essencialmente descentralizada; e

c) uma doutrina comum a todos os órgãos interessados.

Demonstramos, ainda, que seria indispensável, para garantir a adequabilidade e a exeqüibilidade do projeto de funcionamento do BANCO NACIONAL DE DADOS, instituir:

a) Uma LISTA OFICIAL DE ASSUNTOS DE INTERESSE DO GOVERNO, de modo a permitir o conhecimento de todos os dados indispensáveis à tomada de decisões, através do manejo correto das informações, onde seriam realizados, de maneira uniforme e dentro de uma mesma sistemática, comum e global, a coleta, o registro e a apresentação, a análise e a disseminação, permitindo, ainda, o arquivamento segundo uma classificação comum a todos os órgãos, o que garantirá a facilidade de intercâmbio para conhecimento das informações;

b) O NÚMERO DE ESTOQUE BRASILEIRO (NEB);

c) O NÚMERO DE REGISTRO NACIONAL DAS PESSOAS NATURAIS, designação retirada do convênio firmado entre os Ministérios da Justiça, Fazenda, Trabalho e Previdência Social, - que permitirá a individualização de cada pessoa física, com a conseqüente racionalização e simplificação dos serviços pertinentes, garantindo ainda a facilidade de intercâmbio de cadastros.

Procuraremos no presente estudo expandir as nossas idéias sobre a utilização do BANCO NACIONAL DE DADOS na consecução do PLANO NACIONAL DE ESTATÍSTICAS BÁSICAS. 


\section{PLANO NACIONAL DE ESTATISTICAS BÁSICAS (PNEB)}

\section{DEFINIÇÃO DO PNEB}

O Plano Nacional de Estatísticas Básicas (PNEB), aprovado pelo Decreto $n .^{\circ} 63.010$, de 18 de julho de 1968 , tem a seguinte definição:

O PNEB compreende aqueles levantamentos estatísticos necessários ao conhecimento da realidade nacional, em seus aspectos considerados essenciais ao planejamento econômicosocial do País e à segurança nacional.

\section{ESQUEMA DE APRESENTAÇÃO DO PNEB}

O PNEB é apresentado segundo esquema em que se relacionam, distintamente, as estatísticas primárias (apurações de registros ou de levantamentos diretos) e as estatísticas derivadas (resultantes de elaboração com base, geralmente, nas estatísticas primárias). Para cada um dos tópicos enunciados são indicados:

a) a periodicidade com que devem ser pesquisados; e

b) o âmbito geográfico da pesquisa.

Para a periodicidade ou freqüência da pesquisa apresenta o plano uma discriminação coincidente com o tipo de levantamento estatístico a ser realizado para a obtenção das informações. Assim, aos levantamentos censitários é atribuída, na forma da legislação em vigor, a periodicidade decenal ou qüinqüenal, conforme o caso. Com relação às estatísticas contínuas a periodicidade será trienal, bienal, anual, semestral, trimestral ou mensal.

No que se relaciona com o âmbito da pesquisa, o esquema estabelece, sempre que possível, especificação coincidente com a divisão político-administrativa do País. Para certos tópicos estabelece a obrigatoriedade de que sejam disponíveis dados para áreas selecionadas (áreas previamente determinadas para pesquisas específicas, somando no seu conjunto a área total do 
País) e áreas especiais, assim conceituadas as que, por força de lei ou imposição da técnica, sejam representadas por municípios ou distritos de uma ou mais unidades da Federação, cada um deles constituindo área distinta de pesquisa, não somando, necessariamente, a área total do País.

\section{FINALIDADES DAS ESTATISTICAS PARA O GOVERNO}

Podemos dizer que as ESTATÍSTICAS devem ser utilizadas pelo Governo para:

a) prover informações para o planejamento e a tomada de decisões; e

b) controlar as ações planejadas.

Podemos ainda dizer que os esforços desenvolvidos para a obtenção de estatísticas que não atendam às finalidades acima mencionadas devem ser considerados supérfluos, sendo inócuos os gastos consumidos, devendo, conseqüentemente, serem evi-

\section{APRESENTAÇÃO DAS ESTATÍSTICAS}

Os dados estatísticos são, normalmente, apresentados sob duas formas básicas:

a) dados brutos ou estatísticas primárias - aqueles que foram coletados e ainda não sofreram qualquer processo de
análise; e

dos dados coletados secundárias - as resultantes da análise

INSTITUTO BRASILEIRO DE ESTATISTICA (IBE)

O IBE tem por finalidade coordenar as atividades do sistema estatístico nacional, bem como executar levantamentos de estatisticas contínuas e censitárias, e estudos sobre os respectivos resultados, de acordo com as diretrizes e bases fixadas
pela Legislação vigente (Decreto-lei $n .^{\circ} 161$, de $13 / 2 / 67$, art. $9 .^{\circ}$ ).

Caberá, prioritariamente, ao IBE a execução do PNEB, definido pelo Governo, compreendendo as estatísticas essenciais R. Serv. Públ., Brasília, 108 (2): mai./ago. 1973 
ao planejamento econômico-social do País e à segurança nacional (Decreto-lei $n .^{\circ} 161 / 67$, art. $4 .^{\circ}$ ).

A coordenação técnica das atividades do IBE será feita pela Comissão Nacional de Planejamento e Normas Estatísticas (CONPLANE), que foi instalada em 12/12/1967, com a seguinte constituição:

- Diretor-Superintendente do IBE, Coordenador;

- Diretor do Laboratório de Estatística do IBE;

- Diretor do Departamento de Estatísticas Industriais, Comerciais e de Serviços do IBE;

$\mathrm{IBE}$; - Diretor do Departamento de Divulgação Estatística do

- Coordenador-Geral da Rede de Coleta do IBE;

- Diretor-Executivo de Pesquisas Domiciliares do IBE;

- Diretor-Geral de Censos do IBE;

IBE; - Diretor do Centro Brasileiro de Estudos Brasileiros do rias do IBE;

dos do IBE.

- Representante do Instituto Brasileiro de Geografia;

ticas; Representante da Escola Nacional de Ciências Estatís-

- Representante do Estado-Maior da Armada;

- Representante do Estado-Maior do Exército;

- Representante do Estado-Maior da Aeronáutica;

Fun - Representante do Instituto Brasileiro de Economia da 
- Representante do Instituto de Planejamento Econômico e Social, do Ministério do Planejamento e Coordenação Geral;

- Representante do Serviço Técnico de Análise e Planejamento da Secretaria Adjunta para Planejamento Político do Ministério das Relações Exteriores;

- Representante da Superintendência Nacional do Abastecimento;

- Representante do Banco Nacional da Habitação;

- Representante da Federação das Indústrias do Estado de São Paulo;

- Representante da Superintendência do Desenvolvimento do Nordeste;

- Representante da Superintendência do Desenvolvimento da Região Sul.

\section{REDE DE COLETA DO IBE}

A Rede de Coleta de Dados do IBE está sendo reorganizada em função da instituição da Fundação IBGE e deverá ser constituída por 820 Agências distribuídas pelas Capitais dos Estados e principais cidades.

\section{SISTEMÁTICA ATUAL DE OBTENÇÃO DAS ESTATISTICAS BASICAS}

De acordo com o esquema aprovado no PNEB, as estatísticas deverão ser obtidas de acordo com a seguinte periodia) RECENSEAMENTO GERAL - que compreenderá o Censo
Demográfico e os Censos Econômicos: Agrícola, Industrial, Co-
mercial e dos Servicos. mercial e dos Serviços. Complementarmente realizar-se-ão inquéritos especiais sobre "mão-de-obra" e "fluxo de mercadobase em amostia das compras e destinos das vendas), com econômicos. Periodida ser extraída do material relativo aos censos dicidade DECENAL. 
b) CENSOS ECONOMICOS - Periodicidade QÜINQÜENAL.

c) ESTATISTICAS CONTINUAS - Periodicidade TRIENAL, BIENAL, ANUAL, SEMESTRAL, TRIMESTRAL ou MENSAL, conforme as necessidades.

Se atentarmos para o fato de que os dados * tatísticos são levantados através de coletores, principalmente d: ante as épocas de realização do RECENSEAMENTO e dos CENSOS ECONOMICOS, contratados especificamente para tais tarefas, e normalmente despreparados, vinculados à Rede de Coleta de Dados do IBE, poderemos explicar a razão pela qual os resultados obtidos diferem, com margem de até $30 \%$, da realidade, em que pese o vulto dos recursos consumidos. Para o Recenseamento Geral de 1970 foram previstos recursos da ordem de Cr\$200 milhões. Há que fazer ressaltar que tais recursos são consumidos sob a forma de despesas de custeio, sem representar qualquer forma de investimento.

Existem ainda dados, dentro da sistemática atual, que são obtidos pela utilização das técnicas de amostragem, as quais pela utilização, muitas vezes, de coletores eventuais e também não suficientemente capacitados, poderão induzir a graves erros de apreciação, com conseqüências irreparáveis.

Acontece, ainda, hoje em dia, dentro da sistemática atual, que uma mesma instituição é solicitada, por diversas fontes, da mesma ou de diferentes origens, a prestar a mesma informação em diversas ocasiões, o que concorre para encarecer os custos Operacionais, representando despesas inúteis e perda considerável de tempo.

\section{SISTEMATICA PROPOSTA DE OBTENÇÃO DAS ESTATISTICAS BASICAS}

A fim de racionalizar os serviços de obtenção não somente das estatísticas básicas, mas também concorrer para que seja possivel sistematizar o manejo de todas as informações destinadas à tomada de decisões pelo Governo, entendemos que é indispensável instituir: 


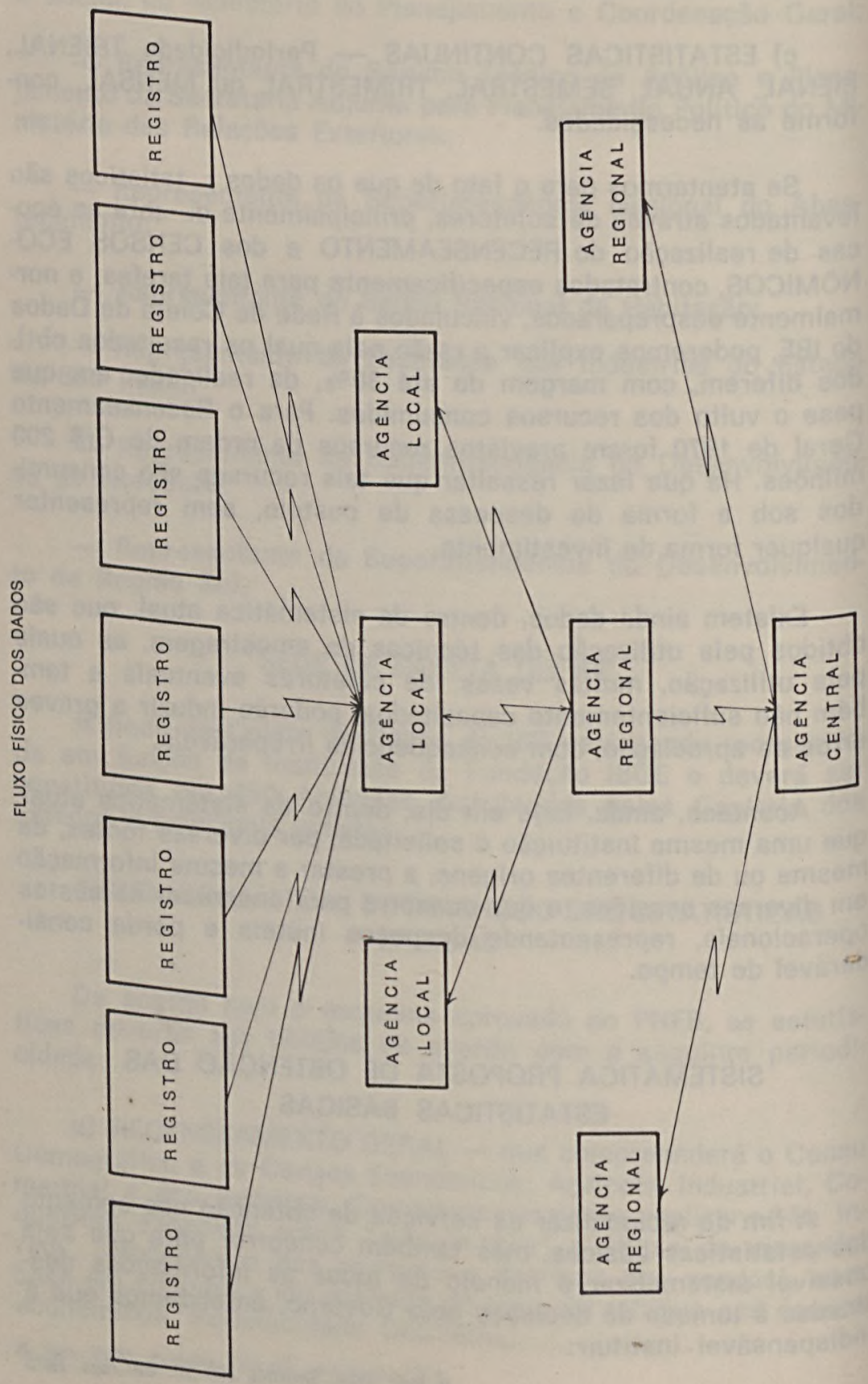


a) O BANCO NACIONAL DE DADOS, fazendo-o funcionar segundo o sugerido no presente estudo;

b) a LISTA OFICIAL DE ASSUNTOS DE INTERESSE DO GOVERNO sugerida, onde deverão ser indicadas as Instituições que deverão exercer a coordenação;

\section{c) O NÚMERO DE ESTOQUE BRASILEIRO (NEB);}

e) O NÚMERO DE REGISTRO NACIONAL DE PESSOAS JU. RIDICAS, de modo semelhante ao das Pessoas Naturais, conforme será tratado mais adiante.

De acordo com a sistemática para utilização do BANCO NACIONAL DE DADOS na obtenção das Estatísticas Básicas, mostrada no artigo anterior, em que não somente foi indicado o "fluxo físico" (Ver a Figura) das informações a seguir transcrito, mas, também, através da indicação das Instituições que deverão, dentro da delegação de competência prevista no artigo 36 do Decreto-lei $n .0^{\circ} 200 / 1967$, alterado por legislação posterior, será possível estabelecer a mais perfeita coordenação e integração de esforços, com a conseqüente economia de meios, na execução do PNEB.

de (1) os DADOS seriam obtidos pelas AGENCIAS LOCAIS ou MUNICIPAIS de acordo com as DIRETRIZES baixadas pelas AGENCIAS REGIONAIS ou ESTADUAIS conforme as solicitações da AGENCIA CENTRAL ou NACIONAL, a tim de atender às NECESSIDADES da POLITICA NACIONAL;

(2) as AGENCIAS LOCAIS ou MUNICIPAIS, coletando, registrando, apresentando $e$ analisando os DADOS obtidos em seus MUNICIPIOS, permitirão às Prefeituras PROGRAMAR as suas ATIVIDADES, de modo a atender às suas NECESSIDADES, dentro da estera de sua competéncia, ao mesmo tempo que Permitiriam encaminhar ao ESTADO as reivindicações de suas atribuiçōes, através da disseminação das análises feitas;

(3) as AGENCIAS REGIONAIS ou ESTADUAIS, recebendo os DADOS lá procossados nos Municipios, fariam a sua integração de modo a, analisando SOb os aspectos REGIONAIS, permitir aos Estados PROGRAMAR os serviços estaduais, estabelecendo as prioridades de acordo com os recursos disponi$\mathrm{V}$ els, de modo a beneficiar a um maior número de Municipios; 
(4) a AGENCIA CENTRAL ou NACIONAL, por sua vez, recebendo das AGENCIAS REGIONAIS OU ESTADUAIS OS DADOS já integrados por REGIAO, procederá à análise em âmbito nacional, PLANEJARA e PROGRAMARA as ATIVIDADES de competência da UNIÃO, de modo a atender às NECESSIDADES GERAIS do Pals.

\section{NÚMERO DE REGISTRO NACIONAL DE PESSOAS JURIDICAS}

Para completar a SISTEMATICA que propomos para a obtenção das Estatísticas Básicas através do BANCO NACIONAL DE DADOS, só nos falta indicar como entendemos que deva ser estabelecido o NÚMERO DE REGISTRO DAS PESSOAS JURIDICAS.

A fim de garantir que o NÚMERO DE REGISTRO NACIONAL DAS PESSOAS JURÍDICAS seja individualizado, entendemos que deverá ser constituído por um conjunto de caracteres alfabéticos, numéricos ou alfa-numéricos, de modo a indicar:

a) $1 .{ }^{\circ}$ SUBGRUPO - a ATIVIDADE PRINCIPAL da Instituição, representada por três (3) caracteres numéricos;

b) 2. SUBGRUPO - O MUNICIPIO em que tiver sido feito o Registro, e indicativo, conseqüentemente, da sede da Instituição, representado por três (3) caracteres numéricos, alfabéticos ou alfa-numéricos;

c) 3. SUBGRUPO - o NÚMERO DE ORDEM DE REGISTRO, dentro de cada Município e por ano, representado por quatro (4) caracteres, normalmente numéricos, podendo ser alfa-numérico, quando o número exceder de 9.999; e

d) 4. SUBGRUPO - O ANO DE REGISTRO, representado pelos dois últimos algarismos do ano. Podemos, portanto, através do NUMERO DE REGISTRO NA-
CIONAL DAS PESSOAS JURIDICAS, como imaginamos, efeti-
vamente, CADASTRAR vamente, CADASTRAR todas as Instituições, assim genericamente designadas as Pessoas Jurídicas existentes no País, sem qualquer dificuldade e sem possibilidade de duplicidade de $r e$ gistro, através de um NúMERO BÁSICO constituído de doze (12) caracteres, bastando, para o conhecimento de suas carac- 
terísticas e outras informações subsidiárias, acrescentar grupos alfabéticos numéricos ou alfa-numéricos.

\section{VANTAGENS DA SISTEMATICA PROPOSTA}

Pelo exposto, podemos afirmar, sem falsa modéstia e sem medo de errar, que a SISTEMATICA por nós idealizada para o manejo das INFORMAÇס̋ES através da instituição:

a) do BANCO NACIONAL DE DADOS;

b) da LISTA OFICIAL DE ASSUNTOS DE INTERESSE DO GOVERNO;

c) do NÚMERO DE ESTOQUE BRASILEIRO (NEB); NATURAIS; $e$

d) do NÚMERO DE REGISTRO NACIONAL DAS PESSOAS

e) do NÚMERO DE REGISTRO NACIONAL DAS PESSOAS JURIDICAS,

permitirá realizar o mais completo e perfeito LEVANTAMENTO ESTRATÉGICO do País, indispensável à tomada de DECISÕES, apresentando as seguintes vantagens principais em relação à sistemática ora utilizada na execução do Plano Nacional das Estatísticas Básicas (PNEB):

(1) racionalização e simplificação dos serviços, através de uma melhor estruturação das organizações administrativas, evitando-se a superposição desnecessária de organizações com idênticas atribuições, segundo os artigos 145 e 146 do Decreto-lei $n .{ }^{\circ} 200 / 1967$, abaixo transcritos:

"Art. 145 - A administração federal será objeto de uma reforma de profundidade para ajustá-la às disposições da presente lei e, especialmente, às diretrizes e princípios fundamentais enunciados no título II, tendo-se como revogadas, por força desta lei, e à medida que sejam expedidos os atos a que se refere o art. 146, parágrafo único, alínea "b", as disposições legais que forem com ela colidentes ou incompatíveis. 
Parágrafo único - A aplicação da presente lei deverá objetivar, prioritariamente, a execução ordenada dos serviços da administração federal, segundo os princípios nela enunciados e com apoio na instrumentação básica adotada, não devendo haver solução de continuidade.

Art. 146 - A reforma administrativa, iniciada com esta lei, será realizada por etapas, à medida que se forem ultimando as providências necessárias à sua execução.

\section{Executivo: \\ Parágrafo único - Para os fins deste artigo, o Poder}

a) promoverá o levantamento das leis, decretos e atos regulamentares que disponham sobre a estruturação, funcionamento e competência dos órgãos da administração federal, com o propósito de ajustá-los às disposições desta lei;

b) obedecidas as diretrizes, princípios fundamentais e demais disposições da presente lei, expedirá progressivamente os atos de reorganização, reestruturação, lotação, definição de competência, revisão de funcionamento e outros necessários à efetiva implantação da re-
forma."

(2) estabelecimento da mais perfeita e completa coordenação e integração de esforços, segundo os Princípios Fundamentais da Reforma Administrativa;

(3) economia de meios;

(4) recuperação das informações através do processamento adequado dos DADOS, utilizando as modernas técnicas de computação eletrônica de dados;

(5) atualização constante e permanente dos DADOS, de modo a permitir que a tomada de DECISÕES seja feita com dados os mais reais possiveis;

(6) efetivo controle das ações planejadas pelo correto acompanhamento das ações desenvolvidas;

(7) integração dos CADASTROS das Pessoas Naturais; e

(8) integração dos CADASTROS das Pessoas Jurídicas. 